\title{
KAS PAUSID KANNAVAD EMOTSIOONI?
}

\section{Kairi Tamuri}

Ülevaade. Pausidele on emotsionaalse kõne uurimustes suhteliselt vähe tähelepanu pööratud. Ilmselt seetõttu, et pausid ei ole esmased emotsiooni kandvad akustilised tunnused. Siiski on teada, et pausidel on emotsioonide eristamisel oma roll. Artiklis antakse vastus kahele küsimusele: kas eestikeelse etteloetud emotsionaalse teksti pausid sõltuvad oluliselt teksti emotsioonist ning kas teksti emotsioon on ära tuntav ainult pausierinevuste põhjal.*

Võtmesõnad: emotsioonide akustika, etteloetud tekst, pausigrupid, pauside arv, pauside asukoht, pauside iseloom, pauside kestus, kõnesüntees, eesti keel

\section{Sissejuhatus}

Emotsioonide lisamine sünteeskõnesse muudab selle palju loomulikumaks ja ilmekamaks ning parandab mõistetavust. Et emotsioone tekst-kõnesünteesi jaoks modelleerida, on vaja üles leida need akustilised tunnused, mis emotsioone kannavad. Enamik kõnesünteesiga seotud uurimustest väidab, et igal emotsioonil on just talle omased akustilised parameetrid (vt Bachorowski 1999). Kirjanduse põhjal võib öelda, et tähtsateks emotsiooni kandvateks akustilisteks tunnusteks peetakse põhitooni ja selle kontuuri, kestust, hääle kvaliteeti, energiat, kõne kiirust, artikulatsiooni täpsust ja intensiivsust, kuid uuritud on ka emotsionaalse kõne pause (Murray, Arnott 2008, Yildirim jt 2004, ten Bosch 2003, Iida jt 2003, Schröder jt 2001, Montero jt 1998).

Uurimistulemused on näidanud, et pausid võivad emotsiooniti erineda nii kestuse kui ka esinemise sageduse poolest. Näiteks eristuvad ingliskeelses kõnes kõige selgemini kurbuselausete pausid. Nende esinemise sagedus on suurem ja võrreldes teiste emotsioonide pausidega on nad pikema kestusega. (Murray, Arnott 2008, Yildirim jt 2004, Schröder jt 2001)

Eestis kõnesünteesi kontekstis emotsioonide akustikat varem uuritud ei ole. Teiste keelte uurimistulemusi ei saa paraku automaatselt eesti keelde üle võtta, sest

* Uurimus on tehtud riikliku keeletehnoloogia programmi projekti "Eesti emotsionaalse kõne korpus", sihtfinantseeri- 
emotsioonide akustiline väljendamine erineb kultuuriti: kõnelemine on kultuuriline tegevus ja igas ühiskonnas on emotsioonide väljendamisel oma reeglid (Burkhardt jt 2006, Douglas-Cowie jt 2003, Scherer 2003). Samuti eelistavad eri keelt kõnelevad inimesed ühte ja sama emotsiooni kuulda sünteeskõnes eri moodi, s.t eri keelte puhul tajutakse sünteeskõne loomulikkust erinevalt (Burkhardt jt 2006).

\section{Uurimisküsimused ja -materjal}

Pausiuurimuse eesmärk oli leida vastus kahele küsimusele: 1) kas eestikeelse etteloetud emotsionaalse teksti pausid sõltuvad oluliselt teksti emotsioonist ${ }^{1}$ ning 2) kas teksti emotsioon on ära tuntav ainult pausierinevuste põhjal.

Esimesele uurimisküsimusele vastuse leidmiseks vaatlesin kolme põhiemotsiooni (kurbuse, viha ja rõõmu) pause. Uurisin pauside arvu, asukohta (sh vastavust kirjavahemärkidele ${ }^{2}$ ), iseloomu (hingamisega $v s$. hingamiseta pausid ${ }^{3}$ ) ning kestust. Uurimismaterjaliks olid sel puhul Eesti Keele Instituudi emotsionaalse kõne korpusest pärit ühe naiskeelejuhi etteloetud ajakirjanduslikud tekstilõigud (vt Altrov 2008). Iga emotsiooni kohta valisin välja keskmiselt 16 lõiku, milles oli 120-123 lauset (vt tabel 1). Sõnesid oli lausetes keskmiselt 8-9, kirjavahemärke oli samuti enam-vähem võrdselt. Pausiuurimuse tulemused esitan ptk 3 .

Teise uurimisküsimuse materjalina kasutasin lõiku, mille laused olid katseisikud kuulamise põhjal määranud neutraalseks. Selle neutraalse lõigu pausiparameetreid muutes viisin läbi kuulamistesti, et teada saada, kas teksti emotsioon on ära tuntav ainult pausierinevuste põhjal. Emotsiooni kuulamistesti tulemused esitan ptk 4.

Tabel 1. Pausiuurimuse materjal

\begin{tabular}{|l|c|c|c|}
\hline & Kurbus & Rõõm & Viha \\
\hline Lõike & 15 & 16 & 18 \\
\hline Lauseid & 120 & 120 & 123 \\
\hline Sõnesid & 1053 & 966 & 1124 \\
\hline Kirjavahemärke & 187 & 181 & 201 \\
\hline
\end{tabular}

\section{Kolme põhiemotsiooni (kurbuse, viha ja rõõmu) pausid}

\subsection{Pauside arv ja asukoht}

Pause oli kurbuselõikudes 165, rõõmulõikudes 181 ja vihalõikudes 195 (vt tabel 2). Pauside arv olenes eeskätt kirjavahemärkide arvust, sest tavaliselt teeb lugeja pausi just kirjavahemärgi kohal (vt Tamuri 2007: 37, Pajupuu, Kerge 2006). Mujal kui kirjavahemärgi kohal tehtud pause nimetatakse lisapausideks. Näiteks on iseloomulik, et lisapausid kipuvad esinema teatud kohtades, milleks on päris- ja kohanimed, numbrid ning sidesõnad (Pajupuu, Kerge 2006).

1 Selles töös ei võrreldud emotsioone neutraalse kõnega, kuna vastav võrdlusmaterjal emotsionaalse kõne korpuses puudub.

2 Jagasin pausid teksti kirjavahemärkidele vastavuse järgi rühmadeks (nt punktipaus, komapaus jne).

3 Hingamisega paus koosneb sissehingamisest, millele eelneb ja/või järgneb vaikus. Hingamiseta paus on selline sõnade või lausete vaheline vaikus kõnes, mille kestus on vähemalt $30 \mathrm{~ms}$. 30 ms sai valitud seepärast, et materjal oleks võrreldav varasemate eesti keelt puudutavate pausiuurimustega, kus pausi miinimumpikkuseks on võetud 30 ms (vt Pajupuu, Kerge 2006, Tamuri 2007: 14). 
Tabel 2. Pauside arv ja asukoht

\begin{tabular}{|l|c|c|c|}
\hline & Kurbus & Rõõm & Viha \\
\hline Pauside arv & 165 & 181 & 195 \\
\hline $\begin{array}{l}\text { Pausid kirjavahemärkide kohal } \\
\text { (\% kõigist pausidest) }\end{array}$ & $92 \%$ & $92 \%$ & $90 \%$ \\
\hline $\begin{array}{l}\text { Lisapausid } \\
\text { (\% kõigist pausidest) }\end{array}$ & $8 \%$ & $8 \%$ & $10 \%$ \\
\hline
\end{tabular}

Kirjavahemärkide kohal tehtud pauside hulk emotsiooniti ei erinenud: kurbuse ja rõõmu puhul langesid 92\% kõikidest pausidest kirjavahemärkide kohale, viha puhul oli see protsent 90.

Emotsiooniti ei erinenud oluliselt ka lisapausid, mis samuti siin uurimuses esinesid kõigil kolmel emotsioonil umbes pooltel kordadel sidesõnade ja/ning ees ja päris- või kohanime ees. Pooltel kordadel olid aga lisapausid juhuslikku laadi ning võisid sõltuda kas teksti sisust või lugejast endast (nt tema kopsumahust).

Analüüsi tulemuste põhjal võib öelda, et pauside arvu ja asukoha poolest kurbuse, rõõmu ja viha emotsioonid üksteisest märgatavalt ei erinenud ning kõigil kolmel langes suurem osa pause kirjavahemärkide kohale.

Kui vaadata erinevaid kirjavahemärke, siis oli koma ainus, mille kohal lugeja pausi alati ei teinud (vt tabel 3). See kehtib kõigi kolme emotsiooni kohta. Komad ongi eesti keeles sellised kirjavahemärgid, mille kohal jäetakse paus tihtipeale tegemata. Ka mõned varasemad uurimused kinnitavad sama (vt Tamuri 2007, Pajupuu, Kerge 2006).

Tabel 3. Komad

\begin{tabular}{|l|c|c|c|}
\hline & Kurbus & Rõõm & Viha \\
\hline Komade arv & 72 & 67 & 80 \\
\hline $\begin{array}{l}\text { Komad, mille kohal paus tehti } \\
\text { (\% kõigist komadest) }\end{array}$ & $51 \%$ & $79 \%$ & $67,5 \%$ \\
\hline
\end{tabular}

Uurimismaterjalis oli emotsiooniti komasid lausetes enam-vähem võrdselt: kurbuselausetes 72, rõõmulausetes 67 ja vihalausetes 80 . Koma kohal tegi lugeja kõige vähem pause kurbuselausetes - umbes pooltel juhtudel. Märkimisväärselt rohkem tegi lugeja koma kohal pause aga viha- ja rõõmulausetes - vastavalt 67,5\% ja 79\% juhtudest.

\subsection{Pauside iseloom}

Pauside iseloomu all pean silmas hingamist. Jagasin pausid hingamisega $v s$. hingamiseta pausideks. Kui pausidele pööratakse kõnesünteesi uurimustes suhteliselt vähe tähelepanu, siis hingamine saab neis veelgi vähem tähelepanu. Samas on näiteks Nick Campbell (1998) väitnud, et hingamise lisamine tõstaks sünteeskõne loomulikkust oluliselt.

Uurisin emotsioonipause hingamise olemasolust lähtuvalt (vt tabel 4). 
Tabel 4. Hingamispausid

\begin{tabular}{|l|c|c|c|}
\hline & Kurbus & Rõõm & Viha \\
\hline Hingamispauside arv & 90 & 96 & 115 \\
\hline Hingamispausid (\% kõigist pausidest) & $54,5 \%$ & $53 \%$ & $59 \%$ \\
\hline $\begin{array}{l}\text { Hingamisega kirjavahemärgipausid } \\
\text { (\% kõigist kirjavahemärgipausidest) }\end{array}$ & $57 \%$ & $56 \%$ & $61 \%$ \\
\hline $\begin{array}{l}\text { Hingamisega lisapausid } \\
\text { (\% kõigist lisapausidest) }\end{array}$ & $31 \%$ & $21 \%$ & $55 \%$ \\
\hline
\end{tabular}

Kõigil kolmel emotsioonil oli hingamispause rohkem kui hingamiseta pause. Enim hingamispause oli vihalausetes, kuid see erinevus teistest emotsioonidest ei ole suur. Olulisem erinevus tuleb sisse lisapausides, kus viha puhul tegi lugeja teiste emotsioonidega võrreldes märgatavalt enam hingamispause.

\subsection{Kirjavahemärkide ja hingamispauside vaheline seos}

Kõige rohkem hingamispause tegi lugeja kurbuse ja rõõmu puhul lause lõpus (vastavalt 68\% ja 67\%), viha puhul aga koma kohal (67\%) (vt tabel 5). Kõige vähem hingamispause tegi lugeja kurbuse- ja rõõmulõikudes koma kohal (vastavalt 27\% ja 36\%), vihalõikudes muude kirjavahemärkide (s.t v.a lauselõpp ja koma) kohal $(56 \%)$.

Tabel 5. Hingamispauside osakaal kirjavahemärkide kohal

\begin{tabular}{|l|c|c|c|}
\hline & Kurbus & Rõõm & Viha \\
\hline Lauselõpp (\% lauselõpupausidest) & $68 \%$ & $67 \%$ & $58 \%$ \\
\hline Koma (\% komapausidest) & $27 \%$ & $36 \%$ & $67 \%$ \\
\hline $\begin{array}{l}\text { Muud kirjavahemärgid } \\
\text { (\% muudest kirjavahemärgipausidest) }\end{array}$ & $60 \%$ & $40 \%$ & $56 \%$ \\
\hline
\end{tabular}

\subsection{Pauside kestus}

Pauside kestus on seotud kõnetempoga. Uurimustest on selgunud, et pausid võivad emotsiooniti erineda ka kestuse poolest. Näiteks ingliskeelses kõnes eristuvad kõige selgemini kurbuselausete pausid, mis on võrreldes teiste emotsioonide pausidega pikemad (Murray, Arnott 2008, Yildirim jt 2004, ten Bosch 2003).

Mõõtsin programmiga Praat (Boersma, Weenink 2009) pauside kestused millisekundites ning jagasin pausid nende iseloomu ja asukoha järgi gruppidesse (vt tabel 6).

Koondtabelist on näha, et kestuste keskmiste järgi olid pikimad pausid kõigil kolmel emotsioonil punktipausid (kurbusel ja rõõmul hingamisega punktipausid, vihal hingamiseta punktipausid) ning kõige lühemad hingamiseta lisa- ja komapausid. 4

Kui võrrelda emotsioonide pausigruppide kestusi omavahel, kooruvad välja mõned olulised erinevused (vt joonis 1). Joonisel 1 on võrdluseks välja toodud ka üks emotsiooniti mitte erinev pausirühm - komad.

4 Arvestatud pole nende pausirühmade andmeid, kus oli ainult üks esindaja. 
Tabel 6. Pausirühmade keskmised kestused (millisekundites)

\begin{tabular}{|c|c|c|c|c|c|c|c|c|}
\hline Märk & Emotsioon & $\mathbf{N}$ & Min & 1. kvartiil & Mediaan & Keskmine & 3. kvartiil & Maks \\
\hline \multirow{3}{*}{ Lisapaus } & kurbus & 9 & 54 & 91 & 117 & 122,4 & 133 & 251 \\
\hline & rõõm & 11 & 34 & 103,5 & 111 & 128,5 & 127 & 359 \\
\hline & viha & 9 & 91 & 119 & 133 & 140,9 & 145 & 267 \\
\hline \multirow{3}{*}{$\begin{array}{l}\text { Hingamisega } \\
\text { lisapaus }\end{array}$} & kurbus & 4 & 300 & 366 & 436,5 & 417,5 & 488 & 497 \\
\hline & rõõm & 3 & 365 & 416 & 467 & 448,3 & 490 & 513 \\
\hline & viha & 11 & 289 & 326 & 399 & 385,6 & 412,5 & 555 \\
\hline \multirow{3}{*}{ Komapaus } & kurbus & 28 & 43 & 113,2 & 203 & 280,2 & 378,8 & 795 \\
\hline & rõõm & 34 & 52 & 137,2 & 222 & 251,7 & 339 & 636 \\
\hline & viha & 21 & 75 & 145 & 207 & 225 & 299 & 428 \\
\hline \multirow{3}{*}{$\begin{array}{l}\text { Hingamisega } \\
\text { komapaus }\end{array}$} & kurbus & 9 & 296 & 394 & 531 & 511 & 615 & 721 \\
\hline & rõõm & 19 & 280 & 407 & 440 & 479,7 & 538,5 & 724 \\
\hline & viha & 33 & 205 & 337 & 408 & 411,7 & 449 & 732 \\
\hline \multirow{3}{*}{ Koolonipaus } & kurbus & 0 & - & - & - & - & - & - \\
\hline & rõõm & 2 & 139 & 180,8 & 222,5 & 222,5 & 264,2 & 306 \\
\hline & viha & 1 & 364 & 364 & 364 & 364 & 364 & 364 \\
\hline \multirow{3}{*}{$\begin{array}{l}\text { Hingamisega } \\
\text { koolonipaus }\end{array}$} & kurbus & 1 & 438 & 438 & 438 & 438 & 438 & 438 \\
\hline & rõõm & 1 & 777 & 777 & 777 & 777 & 777 & 777 \\
\hline & viha & 2 & 296 & 366,5 & 437 & 437 & 507,5 & 578 \\
\hline \multirow{3}{*}{$\begin{array}{l}\text { Mõttekriip- } \\
\text { supaus }\end{array}$} & kurbus & 2 & 837 & 838,2 & 839,5 & 839,5 & 840,8 & 842 \\
\hline & rõõm & 4 & 393 & 526,5 & 606,5 & 628 & 708 & 906 \\
\hline & viha & 5 & 236 & 292 & 525 & 440,8 & 545 & 606 \\
\hline \multirow{3}{*}{$\begin{array}{l}\text { Hingamisega } \\
\text { mõttekriip- } \\
\text { supaus }\end{array}$} & kurbus & 5 & 533 & 987 & 989 & 936 & 1033 & 1138 \\
\hline & rõõm & 3 & 373 & 537,5 & 702 & 603,7 & 719 & 736 \\
\hline & viha & 8 & 316 & 375 & 448 & 526,4 & 693,5 & 865 \\
\hline \multirow{3}{*}{$\begin{array}{l}\text { Mõtte- } \\
\text { punktid }\end{array}$} & kurbus & 5 & 407 & 412 & 786 & 742 & 972 & 1133 \\
\hline & rõõm & 1 & 724 & 724 & 724 & 724 & 724 & 724 \\
\hline & viha & 2 & 878 & 878,5 & 879 & 879 & 879,5 & 880 \\
\hline \multirow{3}{*}{$\begin{array}{l}\text { Hingamisega } \\
\text { mõtte- } \\
\text { punktid }\end{array}$} & kurbus & 8 & 578 & 883,5 & 934 & 911,6 & 987 & 1085 \\
\hline & rõõm & 1 & 474 & 474 & 474 & 474 & 474 & 474 \\
\hline & viha & 0 & - & - & - & - & - & - \\
\hline \multirow{3}{*}{ Punktipaus } & kurbus & 30 & 211 & 637.8 & 913 & 944,4 & 1156 & 2136 \\
\hline & rõõm & 25 & 257 & 524 & 594 & 637,8 & 710 & 1137 \\
\hline & viha & 34 & 426 & 534 & 689 & 690,9 & 805,2 & 1006 \\
\hline \multirow{3}{*}{$\begin{array}{l}\text { Hingamisega } \\
\text { punktipaus }\end{array}$} & kurbus & 54 & 528 & 756,8 & 884,5 & 968,9 & 1076 & 2366 \\
\hline & rõõm & 53 & 413 & 637 & 772 & 773,7 & 882 & 1364 \\
\hline & viha & 43 & 353 & 542 & 667 & 664 & 746 & 1016 \\
\hline \multirow{3}{*}{$\begin{array}{l}\text { Hüüumärgi- } \\
\text { paus }\end{array}$} & kurbus & 0 & - & - & - & - & - & - \\
\hline & rõõm & 7 & 256 & 445,5 & 540 & 570,9 & 708 & 893 \\
\hline & viha & 6 & 384 & 626,5 & 635,5 & 623,7 & 655 & 802 \\
\hline \multirow{3}{*}{$\begin{array}{l}\text { Hingamisega } \\
\text { hüüumärgi- } \\
\text { paus }\end{array}$} & kurbus & 6 & 709 & 813 & 835,5 & 910,8 & 954,8 & 1285 \\
\hline & rõõm & 16 & 383 & 525,8 & 705 & 696,2 & 843 & 996 \\
\hline & viha & 13 & 341 & 600 & 644 & 625,2 & 706 & 719 \\
\hline \multirow{3}{*}{$\begin{array}{l}\text { Küsimärgi- } \\
\text { paus }\end{array}$} & kurbus & 1 & 941 & 941 & 941 & 941 & 941 & 941 \\
\hline & rõõm & 1 & 687 & 687 & 687 & 687 & 687 & 687 \\
\hline & viha & 1 & 532 & 532 & 532 & 532 & 532 & 532 \\
\hline \multirow{3}{*}{$\begin{array}{l}\text { Hingamisega } \\
\text { küsimärgi- } \\
\text { paus }\end{array}$} & kurbus & 2 & 479 & 601,8 & 724,5 & 724,5 & 847,2 & 970 \\
\hline & rõõm & 0 & - & - & - & - & - & - \\
\hline & viha & 1 & 623 & 623 & 623 & 623 & 623 & 623 \\
\hline \multirow{3}{*}{$\begin{array}{l}\text { Küsi-hüüu- } \\
\text { märgipaus }\end{array}$} & kurbus & 0 & - & - & - & - & - & - \\
\hline & rõõm & 0 & - & - & - & - & - & - \\
\hline & viha & 1 & 652 & 652 & 652 & 652 & 652 & 652 \\
\hline & kurbus & 1 & 1260 & 1260 & 1260 & 1260 & 1260 & 1260 \\
\hline küsi-hüüu- & rõõm & 0 & - & - & - & - & - & - \\
\hline märgipaus & viha & 4 & 608 & 619,2 & 638 & 652,8 & 671,5 & 727 \\
\hline
\end{tabular}




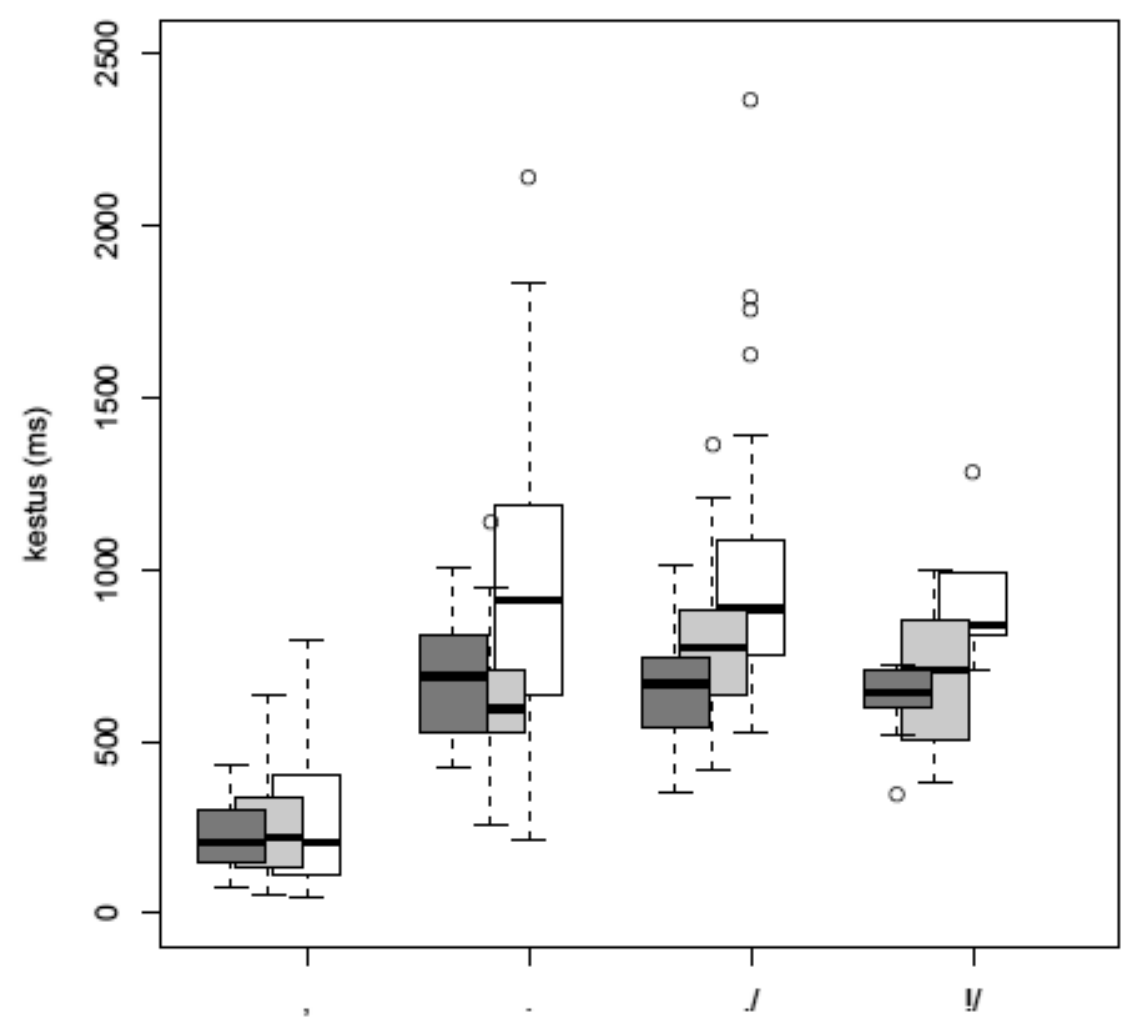

Joonis 1. Statistiliselt oluliselt erinevad pausirühmad (valge tähistab kurbust, helehall rõõmu ja tumehall viha; kaldkriips märgib hingamispause). Joonisel on esitatud iga pausirühma mediaan, esimene ja kolmas kvartiil ning miinimum ja maksimum

Emotsiooniti statistiliselt oluliselt erinevaks $(\mathrm{p}<0,05)^{5}$ osutusid hingamiseta punktipausid, hingamisega punktipausid ja hingamisega hüüumärgipausid (arvutatud kestuse keskmiste põhjal).

- Hingamiseta punktipaus

1. kurbus (944 ms) vs. rõõm (638 ms) $(\mathrm{p}=0,01)$

2. kurbus (944 ms) vs. viha (691 ms) $(\mathrm{p}=0,006)$

- Hingamisega punktipaus

1. kurbus (969 ms) vs. rõõm (774 ms) $(\mathrm{p}=0,000)$

2. kurbus (969 ms) vs. viha (664 ms) ( $\mathrm{p}=0,000)$

3. rõõm (774 ms) vs. viha $(664 \mathrm{~ms})(\mathrm{p}=0,003)$

- Hingamisega hüüumärgipausid

1. kurbus (911 ms) vs. viha (625 ms) $(\mathrm{p}=0,017)$

Pauside modelleerimisel tasub neid erinevusi arvesse võtta.

Ülejäänud pausigrupid kestuselt emotsiooniti oluliselt ei erinenud.

Mõõtmistulemustest selgus, et kõige pikemad pausid olid kurbusel, lühimad aga vihal (kestuste keskmine). See läheb kokku teiste keelte emotsionaalse kõne uurimuste tulemustega. 


\section{Emotsiooni kuulamistest}

Pausiuurimuse tulemustele tuginedes koostasin kuulamistesti, et teada saada, kas teksti emotsioon on ära tuntav ainult pausierinevuste põhjal.

Kuulamistesti aluseks oli (neutraalne) neljalauseline lõik, mille lausetest olid katseisikud (kuulamise põhjal) hinnanud neutraalseks kolm (lõigu esimese, kolmanda ja neljanda lause), ühe (lõigu teise lause) aga rõõmuemotsiooni kandvaks. Puhast, ainult neutraalsetest lausetest koosnevat lõiku korpusest leida ei õnnestunud. Programmi Sound Forge Pro 9 abil muutsin pauside kestust, asukohta ning iseloomu. Nii moodustusid kaheksa erineva pausimustriga lõiku (2 x neutraalne, viha, kurbus ja rõõm). Neli neist olid lihtsama pausimustriga, s.t neutraalses lõigus on muudetud ainult lauselõpupauside kestusi vastavalt pausiuurimuse tulemustele (vt näide 1). Lauselõpupausid valisin välja seepärast, et nende erinevus oli emotsiooniti statistiliselt oluline. Teised neli olid keerulisema struktuuriga (vt näide 2). Neis muutsin nii pauside kestust, iseloomu kui ka asukohta vastavalt pausiuurimuse tulemustele. Neutraalsetes lõikudes ei muutnud ma midagi.

(1) Neutraalne: Klaasipõhja valatakse seda vahest kolm sentimeetrit [./] (456 ms) Ainult tirtsukese rohkem, kui enesest lugupidav sommeljee mekkimiseks pakub [./] (640 ms) Seitsekümmend krooni, palun [.] (495 ms) Aitäh.

Viha: Klaasipõhja valatakse seda vahest kolm sentimeetrit [./] $664 \mathrm{~ms}$ Ainult tirtsukese rohkem, kui enesest lugupidav sommeljee mekkimiseks pakub [./] 664 ms Seitsekümmend krooni, palun [.] 691 ms Aitäh.

Rõõm: Klaasipõhja valatakse seda vahest kolm sentimeetrit [./] 774 ms Ainult tirtsukese rohkem, kui enesest lugupidav sommeljee mekkimiseks pakub [./] 774 ms Seitsekümmend krooni palun [.] 638 ms Aitäh.

Kurbus: Klaasipõhja valatakse seda vahest kolm sentimeetrit [./] $969 \mathrm{~ms}$ Ainult tirtsukese rohkem, kui enesest lugupidav sommeljee mekkimiseks pakub [./] 969 ms Seitsekümmend krooni, palun [.] 944 ms Aitäh.

(2) Neutraalne: Klaasipõhja valatakse seda vahest kolm sentimeetrit [./] (456 ms) Ainult tirtsukese rohkem, kui enesest lugupidav sommeljee mekkimiseks pakub [./] (640 ms) Seitsekümmend krooni, palun [.] (495 ms) Aitäh.

Viha: Klaasipõhja valatakse seda vahest [] $141 \mathrm{~ms}$ kolm sentimeetrit [.] $691 \mathrm{~ms}$ Ainult tirtsukese rohkem [,/] $412 \mathrm{~ms}$ kui enesest lugupidav sommeljee mekkimiseks pakub [./] 664 ms Seitsekümmend krooni, palun [.] 691 ms Aitäh.

Rõõm: Klaasipõhja valatakse seda vahest kolm sentimeetrit [./] $774 \mathrm{~ms}$ Ainult tirtsukese rohkem [,] $252 \mathrm{~ms}$ kui enesest lugupidav sommeljee mekkimiseks pakub [.] $638 \mathrm{~ms}$ Seitsekümmend krooni, palun [./] $774 \mathrm{~ms}$ Aitäh.

Kurbus: Klaasipõhja valatakse seda vahest kolm sentimeetrit [.] $944 \mathrm{~ms}$ Ainult tirtsukese rohkem, kui enesest lugupidav sommeljee mekkimiseks pakub [./] 969 ms Seitsekümmend krooni, palun [./] 969 ms Aitäh. 
Pärast testi koostamist palusin kümnel katseisikul heli põhjal määrata, mis emotsioon lõigus kõlab - kas viha, rõõm, kurbus või on lõik ilma erilise emotsioonita, s.t neutraalne. Testi tulemustest pidi selguma, kas lause emotsiooni saab muuta ainult ühe akustilise parameetri abil, s.t pausiga manipuleerides.

Lõigud, kus oli muudetud ainult lauselõpupauside kestusi (vt näide 1), kõlasid kuulajale endiselt neutraalsena (vt tabel 7). Sama tulemuse sain lausete puhul, kus oli muudetud nii pauside kestust, iseloomu kui ka asukohta (vt näide 2 ja vt tabel 8).

Seega ei suutnud pausid üksinda lõigu emotsiooni muuta.

Tabel 7. Lõigud, kus oli muudetud ainult lauselõpupauside kestus

\begin{tabular}{|l|c|c|c|c|}
\hline \multicolumn{5}{|c|}{ Vastusevariandid } \\
\hline Lõigu emotsioon & Rõõm & Viha & Kurbus & Neutraalne \\
\hline Rõõm & $0 \%$ & $10 \%$ & $0 \%$ & $90 \%$ \\
\hline Viha & $10 \%$ & $10 \%$ & $10 \%$ & $70 \%$ \\
\hline Kurbus & $0 \%$ & $20 \%$ & $10 \%$ & $70 \%$ \\
\hline Neutraalne & $0 \%$ & $20 \%$ & $10 \%$ & $70 \%$ \\
\hline
\end{tabular}

Tabel 8. Lõigud, kus oli muudetud nii pauside kestus, iseloom kui ka asukoht

\begin{tabular}{|l|c|c|c|c|}
\hline \multicolumn{5}{|c|}{ Vastusevariandid } \\
\hline Lõigu emotsioon & Rõõm & Viha & Kurbus & Neutraalne \\
\hline Rõõm & $10 \%$ & $10 \%$ & $10 \%$ & $70 \%$ \\
\hline Viha & $10 \%$ & $10 \%$ & $0 \%$ & $80 \%$ \\
\hline Kurbus & $10 \%$ & $20 \%$ & $0 \%$ & $70 \%$ \\
\hline Neutraalne & $10 \%$ & $10 \%$ & $0 \%$ & $80 \%$ \\
\hline
\end{tabular}

\section{Kokkuvõte}

Pausiuurimus näitas, et eestikeelses emotsionaalses kõnes võivad pausid emotsiooniti erineda nii oma asukoha, iseloomu kui ka kestuse poolest. Kuigi analüüsist selgus, et pauside vahel oli siin-seal emotsiooniti olulisi erinevusi, näitas kuulamistest, et sellest üksinda siiski ei piisa, et kuulajad suudaksid nende põhjal emotsioone üksteisest eristada. Samas ei saa ka väita, et pausidel pole emotsioonide eristamisel üldse mingit tähtsust. Pausid võivad muutuda oluliseks koos teiste emotsioone eristavate akustiliste tunnustega. Kas see nii ka on, seda näitab edasine emotsiooniakustika uurimine.

Pauside arvu, asukoha ja iseloomu analüüsi tulemusi kokku võttes saab esitada mõned soovitused pauside modelleerimiseks sünteeskõne jaoks.

Pauside asukoht - kõigil kolmel emotsioonil tasub pausid panna kirjavahemärkide kohale. Erand tuleb sisse ainult koma juures - rõõmu- ja vihalausetes võib pausi panna ka koma kohale, kurbuselausetes pigem mitte. Kuna lisapauside osakaal oli emotsiooniti väike (8-10\%) ning sõltus pooltel juhtudel kas teksti sisust või lugejast endast, siis lisapause modelleerida ei ole oluline.

Pauside iseloom - kõigil kolmel emotsioonil võib vähemalt pooled pausid modelleerida hingamispausideks. Pausid tuleb teha mõistliku vahemaa tagant, 
intervalli võib arvutada näiteks deklinatsiooni oletatava kestuse järgi. Kui viha puhul ei ole oluline, millise kirjavahemärgi kohale hingamine panna, siis rõõmulausetes sobib hingamine pigem lauselõppu ning kurbuselausetes tuleb jälgida, et hingamine (ja paus) ei satuks koma kohale.

\section{Viidatud kirjandus}

Altrov, Rene 2008. Eesti emotsionaalse kõne korpus: teoreetilised toetuspunktid. - Keel ja Kirjandus, 4, 261-271.

Bachorowski, Jo-Anne 1999. Vocal expression and perception of emotion. - Current Directions in Psychological Science, 8 (2), 53-57. doi:10.1111/1467-8721.00013

Boersma, Paul; Weenink, David 2009. Praat: doing phonetics by computer (Version 5.0.46). http://www.praat.org/ (19.01.2009).

Burkhardt, Felix; Audibert, Nicolas, Malatesta, Lori; Türk, Oytun; Arslan, Levent M.; Auberge, Veronique 2006. Emotional prosody - does culture make a difference? - SP-2006, paper 207.

Campbell, Nick 1998. Where is the information in speech? (And to what extent can it be modelled in synthesis?). - Proceedings of the Third ESCA/COCOSDA Workshop on Speech Synthesis. Australia: Jenolan Caves, 17-20.

Douglas-Cowie, Ellen; Campbell, Nick; Cowie, Roddy; Roach, Peter 2003. Emotional speech: Towards a new generation of databases. - Speech Communication, 40 (1), 33-60. doi:10.1016/So167-6393(02)00070-5

Eesti emotsionaalse kõne korpus. http://193.40.113.40:5000 (29.09.2009).

Iida, Akemi; Campbell, Nick; Higuchi, Fumito; Yasumura, Michiaki 2003. A corpus-based speech synthesis system with emotion. - Speech Communication, 40 (1), 161-187. doi:10.1016/So167-6393(02)ooo81-X

Montero, Juan Manuel; Gutierrez-Arriola, Juana M.; Palazuelos, Sira; Enriquez, Emilia; Aguilera, Santiago; Pardo, José Manuel 1998. Emotional speech synthesis: from speech database to TTS. - ICSLP-1998, paper 1037.

Murray, Iain R.; Arnott, John L. 2008. Applying an analysis of acted vocal emotions to improve the simulation of synthetic speech. - Computer Speech and Language, 22, 107-129. doi:10.1016/j.csl.2007.06.001

Pajupuu, Hille; Kerge, Krista 2006. Hingav süntesaator ja pausid tekstiliigiti. - Keel ja Kirjandus, 3, 202-210.

Scherer, Klaus R. 2003. Vocal communication of emotion: A review of research paradigms. Speech Communication, 40 (1), 227-256. doi:10.1016/So167-6393(02)ooo84-5

Schröder, Marc; Cowie, Roddy; Douglas-Cowie, Ellen; Westerdijk, Machiel; Gielen, Stan 2001. Acoustic correlates of emotion dimensions in view of speech synthesis. EUROSPEECH-2001, 87-90.

Tamuri, Kairi 2007. Pausid etteloetud ilukirjandustekstis. Magistritöö. Käsikiri Tallinna Ülikooli eesti keele ja kultuuri instituudis.

ten Bosch, Louis 2003. Emotion, speech and the ASR framework. - Speech Communication, 40 (1), 213-225. doi:10.1016/So167-6393(02)00083-3

Yildirim, Serdar; Bulut, Murtaza; Lee, Chul Min; Kazemzadeh, Abe; Deng, Zhigang; Lee, Sungbok; Narayanan, Shrikanth; Busso, Carlos 2004. An acoustic study of emotions expressed in speech. - INTERSPEECH-2004, 2193-2196.

Kairi Tamuri (Eesti Keele Instituut) uurimisvaldkond on emotsionaalse kõne akustika.

kairi.tamuri@eki.ee 
Kairi Tamuri

Institute of the Estonian Language

Pauses have received relatively little attention among the researchers of emotional speech. It may be caused by the fact that pauses are not considered to belong to the primary acoustic parameters rendering emotions. However, they do help to distinguish between emotions (Murray, Arnott 2008, Yildirim et al. 2004, ten Bosch 2003, Iida et al. 2003, Schröder et al. 2001, Montero et al. 1998).

This research looks for an answer to two questions: 1) if the pauses in an emotional text read out in Estonian differ considerably depending on the emotion of the text; 2) if the emotion contained in the text can be recognised by looking at the pause differences only.

Although the research proved that some pauses differ by emotion, the perception test shows that this parameter alone is not sufficient to distinguish between emotions.

Keywords: acoustics of emotions, read out text, pause groups, number of pauses, location of pauses, character of pauses, duration of pauses, speech synthesis, Estonian 